\title{
Peer Mentoring and Its Implications in Students Support and Management in Secondary Schools in Kenya: A Case of Friends School Kamusinga (FSK), Bungoma County, Kenya
}

\author{
David Kipkasi Kessio \\ Moi University, School of Education, P.O Box 3900-30100, Eldoret, Kenya
}

\begin{abstract}
This paper reviews peer mentoring in Kenya which enables new students to be provided orientation by more senior peers. Peer mentors serve as their mentees thus make the transition to secondary schools smooth. Peer mentoring is an educational model that builds on peer support and mentoring to assist young learners to enhance social relationships, develop cognitive skills, and promote positive identity development in schools and instill discipline which this paper explores. It adopted Albert Bandura's reciprocal determinism model. The study used qualitative research design where focused group discussion (FGD), participant observation, interview guide and document analysis was used to collect data. The class teachers, senior teachers, Dean of students and students' counselors including the school management were key informants. Ten FGD were interviewed. Research findings revealed that there was greater sense of self awareness and adjustment of the new students due to interaction and positive guidance by mentors. The new comers were able to be guided thus easy adjustment. Study revealed that few cases of indiscipline cases and attempted strikes were reported thus improved academic performance. Peer mentoring of new students with senior students have the transformative space to articulate their worldview and thinking. They can engage in peer feedback where they are positioned as leaders in the foreseeable future. The study findings are significant to educational managers in schools, Ministry of education and researchers on students' welfare, discipline, modeling and support.
\end{abstract}

Keywords: peer mentoring; discipline; adjustment; mentee; social relationship, role model

DOI: $10.7176 / \mathrm{JEP} / 10-35-09$

Publication date: December $31^{\text {st }} 2019$

\section{Introduction}

Peer mentoring as an orientation programme is a form of mentorship that usually takes place between a person who has lived through a specific experience (peer mentor) and a person who is new to that experience (the peer mentee) such as enrolment in the school. Most peer mentors are selected for their sensibility, confidence, social skills and reliability (Leidenfrost et.al., 2011; Kieran \& O'Neill, 2009). Peer mentoring programs are an important component in the strategy to enhance the new students' adjustment in the new school. The operation of these programs ought to be informed by evidence as to their effectiveness (Jennifer \& Dianne, 2014).

Peer support, tutoring programs and peer counseling have a decades-long history in the United States, European countries and relatively new in developing countries and particularly African context. Peer mentoring has been distinguished from such approaches. Some peer-to-peer programs aim at enhancing academic performance; others focus on social and emotional functioning (Leidenfrost et.al., 2011; Willis, et.al. (2012).

Empirical research on mentoring of young people from America has focused upon the 'classic model' of mentoring, that of a one - to - one relationship between an adult and a young person (Dubois, 2002; Jennifer \& Dianne, 2014). This study interrogates Albert Bandura (2002) reciprocal determinism model as used in peer mentoring programmes in schools. Mentoring work include; selecting an appropriate tasks for the role of mentor, describing their responsibilities, advising and making it easy to respond, screening candidates for readiness, making a suitable match with the mentee, orientation of mentors to the new roles and making it priority to the mentors (Adelman \& Taylor, 2010; Jennifer \& Dianne,2014;Willis, et.al., 2012. It is more of a calling and proactive strategy for school management to improve school climate ultimately and culture thus improved performance.

\section{Review of key literature}

Empirical studies reveal that that new students would benefit immensely from having a positive, caring, experienced role model. At schools, there are a range of senior peers who could be such models. At the same time, it is clear that many students do not have regular personal connections to an adult at school. This is where mentoring programs could help bridge a critical gap. The benefits of mentoring programs are described not only as supporting individual students but as contributing to establishment of a safe and positive school climate thus curtail indiscipline cases (Adelman \& Taylor, 2010; Willis, et.al., 2012; Pascarella \& Terenzini, 2005).

Peer mentors have been described as knowledgeable guides for new students, facilitators providing access to people and resources, role models and advocates. They support transitions and help mentees navigate daily 
challenges confounding the new students (Adelman \& Taylor, 2010; Willis, et.al., 2012). In this study, reciprocal determinism posits that behavior is controlled or determined by the individual, through cognitive processes, and by the environment, through external social stimulus events. So in the case of our troubled new student, his/her dislike of school is being reinforced (and perhaps magnified) by the actions of his teachers and classmates, which he's perpetuating by continuing to act out ( Bandura,2002 ; Jennifer \& Dianne,2014).

Peer mentors may be seen as able to connect easily with mentees; they also spend more time with their mentees. In addition, some parents of mentees may feel more comfortable with a student mentor designated by the school rather than an adult volunteer (Jennifer \& Dianne, 2014 Bruce \& Bridgeland, 2014). Peer mentorships also have the potential benefits of generating a double impact (i.e., both mentors and mentees could benefit). Empirical research is limited. Available anecdotal results reported positive impact of peer mentoring. Potential benefits for mentees are feelings of connectedness to school, competency, grades, enhanced social behaviors and attitudes, and self-efficacy (Adelman \& Taylor, 2010; Bruce \& Bridgeland, 2014).

Positive results reported for mentors included enhanced personal and interpersonal skills and connectedness to school, increased confidence, self-esteem, empathy and moral reasoning, intrapersonal communication and conflict resolution skills, and relationships with parents (Adelman \& Taylor,2010; Bruce \& Bridgeland, 2014). Mentor preparation is an added value to their education. Notably, for secondary school peer mentors, the activity could strengthen their college and work applications. All students would benefit from mentoring and some could have been at risk for negative effects. The selection criteria and process required careful planning and implementation; particular concern was how the decision would be made if a student did not want a mentor assigned (Heirdsfield et.al., 2008).

Mentoring presents myriad opportunities and prospects, in that the programmes elicit a variety of tangible outcomes for the mentee, mentor and the school consequently community at large. The explicit and implicit benefits of the mentoring programme are to enable new students explore their strengths and weaknesses in a confidential environment, always being able to find a source of help, reduced amount of attrition or drop outs; and for the mentors, building their experiences and satisfaction of assisting other students (Bruce \& Bridgeland, 2014; Adelman \& Taylor,2010; Willis, et.al. (2012).

Tabbron et al. (1997) found that an important advantage of mentoring is the structure it gives to explore strengths and weaknesses in a confidential atmosphere. His survey of students who had taken part in mentoring schemes found that mentees often saw the mentors as a "mirror" or role model. Student mentors take responsibility for and contributing to a supportive environment for all pupils (Baginsky, 2004). It provides social and developmental support to mentees (Bruce \& Bridgeland, 2014; Bandura, 2002). Benefits which accrue to respective mentors include raised self - esteem, social insight and development of interpersonal skills which are soft skills required in $21^{\text {st }}$ century.

Empirical studies suggest that training is a central feature of success (Bruce \& Bridgeland, 2014 Willis, et.al., 2012). Training should include preliminary information on characteristics including expectations about the first year students, mentors roles and expectations; building lasting relationships and communication skills. In addition, ongoing trainings should focus on issues such as socio - economic, diversity and cultural sensitivity, skills for setting limits with their mentee, problem- solving skills, and conflict resolution strategy (Baginsky, 2004; Bruce \& Bridgeland, 2014; Tabbron et al.,1997).

\section{Statement of the problem}

Transition from primary to secondary school is inevitably a challenging life situation for young learners, as it involves social- emotional and economic changes. New students have to organize their own learning, manage their new study time and social schedules, build new social networks and friendships, and adjust to the requirements of the new secondary school system of learning and teaching (Pascarella \& Terenzini, 2005). It is evident that some new comers had never stayed away from their parents and nuclear families. Empirical research reveals some form of bullying of new comers by senior learners (Bruce \& Bridgeland, 2014).

Peer mentoring provides a form of 'brother's keeper' role thus smooth adjustment and new orientation into the new school. The purpose of this study was to explore mentoring and its role in students support and management in secondary schools in Kenya. There is paucity of empirical evidence of peer mentoring in schools in Kenya. It was guided by the following objectives:- to establish process of students mentoring programmes, strategies and the benefits of peer mentoring in the management of secondary schools; it also suggested policy options for improvement at Friends School, Kamusinga ( FSK)

\section{Theoretical framework}

The study adopted Albert Bandura (2002) reciprocal determinism model which foregrounds three factors that influence behavior namely: - the environment, the individual, and the behavior itself. According to this theory particular study, a peer mentor and mentee's behavior influences and is concomitantly influenced by both the social world and personal characteristics. Merriam (1998) states that qualitative case studies in education are often 
framed with concepts, models and theories (P: 19). An inductive method was then used to support or challenge inherent theoretical assumptions. Although the research process in this particular qualitative research was inductive, Merriam P: 49; posits that most qualitative research inherently moulds or changes existing theory in that:

Data are analyzed and interpreted in light of the concepts of a particular theoretical orientation;

Findings are usually discussed in relation to existing knowledge (some of which is theory) with the aim of delineating how the present study has contributed to expanding the knowledge base.

Reciprocal determinism in this particular study suggested that peer mentees play a much more active and interactive role. They do not simply react as a result of learned associations or reinforcements from mentors and school fraternity; their own personal characteristics, thoughts, feelings, and behaviors impact on how they interact with their peers and the world at large (Bandura, 2002) as illustrated in Figure 1. Social learning theory emphasizes that behavior; personal characteristics; and environmental factors are all equal, interlocking determinants of each other. He referred to this concept as reciprocal determinism.

Bandura (2002) believed that behavior itself influences both the person and the environment, each of which subsequently affects behavior of both mentee and mentor in particular. It results in a more complex interplay of factors known as reciprocal determinism as demonstrated in figure 1. Bandura believed that individual such as mentors and mentees in this particular study could intentionally act as change agents within their environment such as school and the society; thus altering the factors that determine their behavior. It is evident that we have the freedom to influence that which determines our behavior.

The school management strategically uses individual behavior and personal factors of both mentors and mentees to create high sense of agency and efficacy in ambience, environment of peer mentoring process. These would curtail indiscipline cases and improved school climate. Bandura goes on to say that given the same environmental constraints, individuals who have many behavioural options and are adept at regulating their own behavior will experience greater freedom than will individuals whose personal resources. Peer mentoring is beneficial to all and sundry and could complement the students' guild and leadership in the management of school since there is one- to- one interaction and modeling.

\section{Study location and target population}

The study was conducted at Friends School Kamusinga (FSK), a boy secondary school located in Kimilili, Bungoma County in Kenya. Quakers national secondary school established in 1956. Located 400 kilometres west of Nairobi, Kenya capital city. It is one of the leading schools in terms of academic performance and extracurricular activities such as hockey, basketball, and rugby. The school practices peer - mentoring programme which is not most commonly practiced in Kenyan secondary schools thus purposely selected. The target population comprised of mentors, mentees, school principal, deputy principal, Dean of students, Boarding masters, students councils/prefects and students counselors.

\section{Research Methodology}

Research designs are plans and the procedures for research that span the decisions from broad assumptions to detailed methods of data collection and analysis (Creswell, 2012). The study adopted interpretivism philosophical paradigm. Qualitative research methodology was used which is a systematic inquiry into the nature or qualities of complex social group behaviours by employing interpretive and naturalistic approaches (Christian, 2000; Creswell, 2012).

Qualitative studies lend itself to thick narrative description of the peer mentors and mentees behaviours in the group's school community natural environment (Christian, 2000; Creswell, 2012). It attempts to be nonmanipulative and took into account the unperturbed views of the participants as the purpose was generally aimed for objectivity. Qualitative research was most appropriate since the researcher set out to become more familiar with the phenomenon of peer mentoring, to achieve a deep understanding of how people think about role of peer mentoring and to describe in great detail the perspectives of the research participants in their natural setting (Ajzen, 2011; Adelman \& Taylor, 2010).

In this study, the researcher was considered the primary instrument of data collection and analysis through focused group discussions (FGD), participant observation of role play and document analysis of students' records. The researcher engaged the situation, made sense of the multiple interpretations thereof; as multiple realities exist in any given context as both the researcher and the participants construct their own realities. He strived to collect data in a rather non-interfering manner, thus attempted to study real-world situations as they unfolded naturally in FSK school environment without predetermined constraints or conditions that could control the study or its outcomes. Merriam (1998) aptly put:-

she/he engages the situation most often without an observation schedule, and plays a dynamic role in constructing an understanding of the research environment through self interpretation of what happens... thus, qualitative research produces a result which is "an interpretation by the researcher of others' views filtered through his or her own"( P:23). 
Focused group discussion was used where the researcher asked the questions in sequence and rephrased in order to get the required data (Kessio, 2011; Cohen et.al., 2007). The respondents were requested to consent to be audio-taped as the researcher made notes and summary during the observation and FGD interview sessions. Participant observation was used. It was quite challenging and thus was personally undertaken by the researcher since he had to play the advocate role at some instances to get more data and established good rapport with the respondents. Focused group discussions consisted of between six (6) to eight (8) respondents per group drawn from the six (6) form one streams who also provided their views on the role of peer mentoring and concomitantly how it could be improved. The mentors and teachers corroborated the findings as a form of triangulation.

Data was analyzed through thematic coding and transcriptions of audio-taped narratives from the respondents. Counter - checking and triangulation of findings was systematically done.

\section{Ethical Considerations in Data Collection}

Educational researchers have a responsibility to ensure that in whatever research paradigm they work, their research is enacted within a rigorous framework that addresses the epistemological complexities of a study's methodological process and intellectual focus in an ethical manner that allows the recipients of the research to have trust in its outcomes (Nalita \& Hugh, 2007; Christian, 2000; Creswell, 2012).

Christians (2000) goes on to tell us and explain in detail what these four guidelines are, namely: informed consent: Subjects must agree voluntarily to participate, this agreement must be based on full and open information; deception, deliberate misrepresentation is forbidden; privacy and confidentiality, privacy safeguard against unwanted exposure, made public only behind a shield of anonymity, no one deserves harm or embarrassment as a result of insensitive research practices and lastly accuracy ( Nalita \& Hugh, 2007; Cresswell, 2012).Permission was sought from the school management and confidentially upheld at all moments. The names of the respondents were not made public including those findings which could be adverse to the school management.

In summary, the research study adhered to the Belmont Report (1979) as cited in Christian (2000) and Creswell (2012) which defined three basic principles that apply to all research with human participants. Respect for person's states research participants should be autonomous and allowed to make their own decisions and that participants with limited autonomy in this case students deserve special treatment. Beneficence intimates that research participants must have their well - being protected always. Beneficence embodies two elements: do not harm and maximize benefits while minimizing harm. Justice divides the burdens and benefits equally between the researcher and participants. The findings from the study would benefit the respondents and the school management to improve the peer mentoring programme to the benefit of respondents and school at large.

\section{Discussion of the key findings}

Findings indicated that new students who had good mentors were more likely to remain in school until they sat for their summative Kenya certificates of secondary education (KCSE); were also reportedly more successful in class work due to social adjustment at the onset. The research findings revealed that peer mentoring could contribute significantly to the retention and good discipline of students in several ways. The respondents attested that their mentors inspired them with the FSK school motto "use common sense". Notably; the school operated without formal written rules and regulations but adhered religiously to their school motto which was a departure from other similar schools.

The findings through thematic coding revealed that peer mentors assisted in the recruiting of students through positive image of the school, simply by getting in touch with admitted students and answering questions about the program, the school, the academic culture and their expectations. The peer mentor supported incoming students become established in the school community (with advice on hostel, shopping, finding school common amenities, leisure-time activities such as swimming, drama, games, debate, choir among other extra-curricular activities. It supports the findings by Heirdsfield et.al. (2008). Interview schedule revealed that peer mentor helped students understand subjects/program expectations or policies.

Mentees and mentors were inherently highly satisfied with mentoring. Nevertheless, problems existed, such as conflict between the mentoring and supervisory roles of the mentor, confidentiality breaches, mentor bias, lack of "active listening" and role confusion. Problems usually stemmed from poor implementation of mentoring. Prefects and students representatives who by large extent were supervisors were reported not to have been effective mentors due to conflict of interest. Teachers acted as referees and mediators in conflict resolution. The findings revealed school management support to peer mentoring programs which supported findings by Adelman \& Taylor (2010). The time of engagement was reportedly short.

A peer mentor could accompany new students to events hosted by the school (whether academic, such as guest speaker, preaching events, or social). A peer mentor could help new pupils identify teachers and clubs patrons whose interests were aligned with theirs and whom they could consult them regularly. These were evidenced by clubs and societies including the elective subjects chosen by the new learners (Jennifer \& Dianne, 2014; Willis, et.al. 2012). It was established that mentoring was an important developmental process for all involved. There was 
a perception amongst mentors and mentees that in a well conducted programme would provide a win - win situation (Merriam, 1998; Arendal, 2007). They indeed fitted and understood the challenges and opportunities of mentees. Notably, well timed mentoring could reap enormous benefits for mentees; was also useful to mentors, schools and the society at large.

It was reported that all mentees received face-to -face mentoring as well and met their peer mentors regularly during free times such as games, evenings and weekends. One of the major concerns reported on mentoring was that it was time consuming since the mentees who were senior students were equally busy with their studies. There were also very paltry reported cases of slight disagreements between mentees and mentors due to socio - cultural backgrounds, personal and perceptions which were resolved swiftly by the class teachers, teachers on duty, Dean of students and the deputy principals who were in charge of discipline and peer mentoring process. This supports the findings from (Arendal, 2007; Jennifer \& Dianne, 2014).

Mentees got appropriate support on some pertinent issues. Namely; it was an integral task for the peer mentor to discuss the mentees' individual learning schedules, to inform their mentees about their own shared experiences from time to time (Bruce \& Bridgeland, 2014; Adelman \& Taylor,2010). Documents analysis review of students' progress revealed marked improvement and limited reported indiscipline cases. It was also documented as a form of training to the mentees who were also expected to mentor others in the subsequent years of their schooling. It was reiterated by the respondents that the time was very limited for mentoring process; engagement and adjournment process was albeit ad-hoc and needed to have been well structured. They were ultimately expected to be well disciplined and ultimately responsible citizens as espoused by Ominde report (1964) which formed the basis for goals of education in use in Kenya.

Generally, findings seemed to have been consistent with other related empirical studies on mentoring programs which revealed positive effects on indicators of academic performance like improved grades or academic performance, study progress, drop-out rates, and/or study persistence and resilience ( Leidenfrost et.al., 2011; Adelman \& Taylor, 2010) and limited reported indiscipline cases. Notably, the old boys were not involved in peer mentoring.

\section{Implications and Conclusions}

Empirical evidence through thematic coding document analysis revealed by the peer mentees and mentors narratives including schools staff members; tasked with support together with other key informants highlighted the explicit and implicit benefits experienced by those involved, in addition to the school management at large. The findings offer potential implications for school and national policies hitherto. School management should continue to offer support programs especially mentoring transition from primary to secondary schools. The mentorship program can complement the students' guild leadership program in schools. The study provided insight on the role of peer mentoring in secondary schools in Kenya which is neither widely nor formally practiced countrywide.

The findings from this study are limited to Friends School Kamusinga (FSK) and cannot be generalized to the entire country. Any attempted generalization should take due consideration of the study population. Improvement of the mentoring programme in the long term would be to ensure feedback through evaluation was obtained from each cohort of mentees and mentors in order to find out inherent strengths and weaknesses. This means that the weaknesses could be addressed and improved and the strengths enhanced. In summary; positive outcomes are supportive policy practices, an effective and efficient including; operational strategies for continued effective implementation and sustainability in the foreseeable future of peer mentoring in schools.

\section{Key Policy Recommendations}

The following recommendations should be taken into consideration by the school management, relevant stakeholders and the Ministry of Education responsible for education provision in Kenya:-

1) There was need to operationalise 'formalized' peer mentoring programme through inclusion in school mission, vision, goals and objectives. Also, enlist Parents support in the peer mentoring programme through Parents Teachers Associations (PTA) and Board of Management (BOM).

2) Communicate or visit schools with stronger peer mentoring programmes for benchmarking of the best practices and synergy

3) Introduce regular training for mentees similar to that provided for mentors (e.g list of outcomes of what they expect from it). Mentees expect greater clarity on what to expect from the process and regular evaluation for feedback and prevent unexpected malpractices. Sensitization of all staff members on peer mentoring should be done regularly in order to create environment of openness and institutionalized process.

4) There was need to reward through pecuniary and non - pecuniary benefits the respective mentees and mentors who perform exemplary and actively participate in the school's academic and extracurricular activities for reinforcement and motivation. 
5) School management, and peer mentors should enhance provision of equity, opportunity and sense of fulfillment for students to realize their innate potentials. Schools must continuously transform how they connect with parents/guardians, old boys association members and stakeholders regularly so that they could work together in furtherance of shared goals in reciprocal determinism manner.

\section{References}

Adelman, H.S., \& Taylor, L. (2010). Mental health in schools: Engaging learners, preventingProblems, and improving schools. Thousand Oaks, CA: Corwin Press.

Ajzen, I. (2011), 'Nature and operation of attitudes", Annual Review of Psychology, (52), 27-58.

Arendale, D. R. (2007). Postsecondary peer cooperative learning programs: Annotated Bibliography. Minneapolis, MN: College of Education and Human Development, University of Minnesota.

Baginsky, M. (2004). Peer Support: Expectations and Realities. Pastoral Care.3-8.

Bandura, A. (2002). "Social cognitive theory in cultural context". Journal of Applied Psychology: An International Review, 51, 269-290.

Bruce, M., \& Bridgeland, J. (2014). The mentoring effect: Young people's perspectives on the outcomes and availability of mentoring. Boston, MA: MENTOR: The National Mentoring Partnership. $\mathrm{http}$ //www.mentoring.org/program-resources/mentor-resources-and-publications/the-mentoring-effect/

Christians, C.G. (2000) 'Ethics and politics in qualitative research', in Denzin, N.K.and Lincoln, Y.S. (eds) Handbook of Qualitative Research, London: Sage Publications.Cohen L.,Manion,L \&Morrison,K.(2007).Research Methods in Education. New York. Routledge

Creswell, J.W. (2012).Research Design:Qualitative,Quantitative and Mixed Method Approaches ,Sage Pub.,Inc. California

Dubois, D. L., Holloway, B. E., Valentine, J. C. \& Cooper, H. (2002) Effectiveness of mentoring programs for youth: A meta-analytical review, American Journal of Community Psychology, 30 (2), 157-197.

Hall, R. (2007). Improving the Peer Mentoring Experience through Evaluation. The Learning Assistance Review, 12(2), 7-17

Heirdsfield, A. M., Walker, S., Walsh, K., \& Wilss, L.(2008). Peer mentoring for first-year Teacher education students: The mentors' experience. Mentoring \& Tutoring: Partnership in Learning, 16(2), 109-124

Jennifer C. \& Dianne S. (2014) "Dialogic peer coaching as teacher leadership for professional inquiry", International Journal of Mentoring and Coaching in Education, 3 (2) 108-124, https://ezproxy.mu.ac.ke:2065/10.1108/IJMCE-03-2013-0022

Kasra Taherian \& Mina Shekarchian (2008) Mentoring for Doctors. Do Its Benefits Outweigh Its Disadvantages? Medical Teacher, https://doi.org/10.1080/01421590801929968 Leidenfrost, B., Strassnig, B., Schabmann, A., \& Carbon, C. C. (2009). Improvement of the study situation for beginners through cascaded blended mentoring (Verbesserung der studiensituation für StudienanfängerInnen durch cascaded blended mentoring). Psychologische Rundschau, 60(2), 99- 106.doi:10.1026/0033-3042.60.2.99

Leidenfrost, B., Strassnig, B., Schabmann, A., Carbon, C.C., \& Spiel, C. (2011). Peer mentoring styles and their contribution to academic success among mentees: A person-oriented study in higher education. Mentoring \& Tutoring: Partnership in Learning, 19(3), 347-365.doi:10.1080/13611267.2011.597122

Kessio,D,K.(2011). Determinants of Enrolment in Universities: Comparative study of Moi and Kampala International Universities, Lambert Academic Publishing, Germany

Kieran, P., \& O’Neill, G. (2009). Peer-assisted tutoring in a chemical engineering curriculum: Tutee and tutor experiences. Australasian Journal of Peer Learning, 2(1), 40-67

Merriam,S.B (1998).Qualitative Research and case Study Applications in Education, Jossey- Bass Publishers, San Francisco

Nalita, J \& Hugh, B. (2007). Ethical Issues in Online Educational Research: Protecting Privacy, Establishing Authenticity in Email Interviewing, International Journal of Research \& Method in Education, 30 (1) 101113, Taylor \& Francis, available Online, Http://Collections.Lib.Uwm.Edu/Cipr/Image/479.Pdf

Pascarella, E. T., \& Terenzini, P. T. (2005). How college affects students: A third decade of research. San Francisco, CA: Jossey-Bass

Republic of Kenya (1964). The Kenya Education Commission Report. Govt. Printers. Nairobi

Tabbron, A., Macaulay, S., \& Cook, S. (1997). Making mentoring work. Training for Quality, 5(1) 6-9.

Willis, P., Bland, R., Manka, L. \& Craft, C. (2012). 'The ABC of peer mentoring -what secondary students have to say about cross-age peer mentoring in a regional Australian school.' Educational Research and Evaluation, $18(2)$, pp. 173-185.

Author Profile: He holds PhD. In Educational Management. He is a DAAD alumni. Teaches at Moi University, School of Education, Educational Management \& Policy Studies Department. He is responsible for Outreach and Extension programmes in the school and has experience in students welfare having served as an Assistant Dean 
of students, Campus Co-ordinator and Mentoring programmes in Moi University. He is the Representative of Technical and Higher Educational institutions in the Revolving Fund Board of Uasin Gishu County, Kenya

Figure 1.Reciprical determinism model

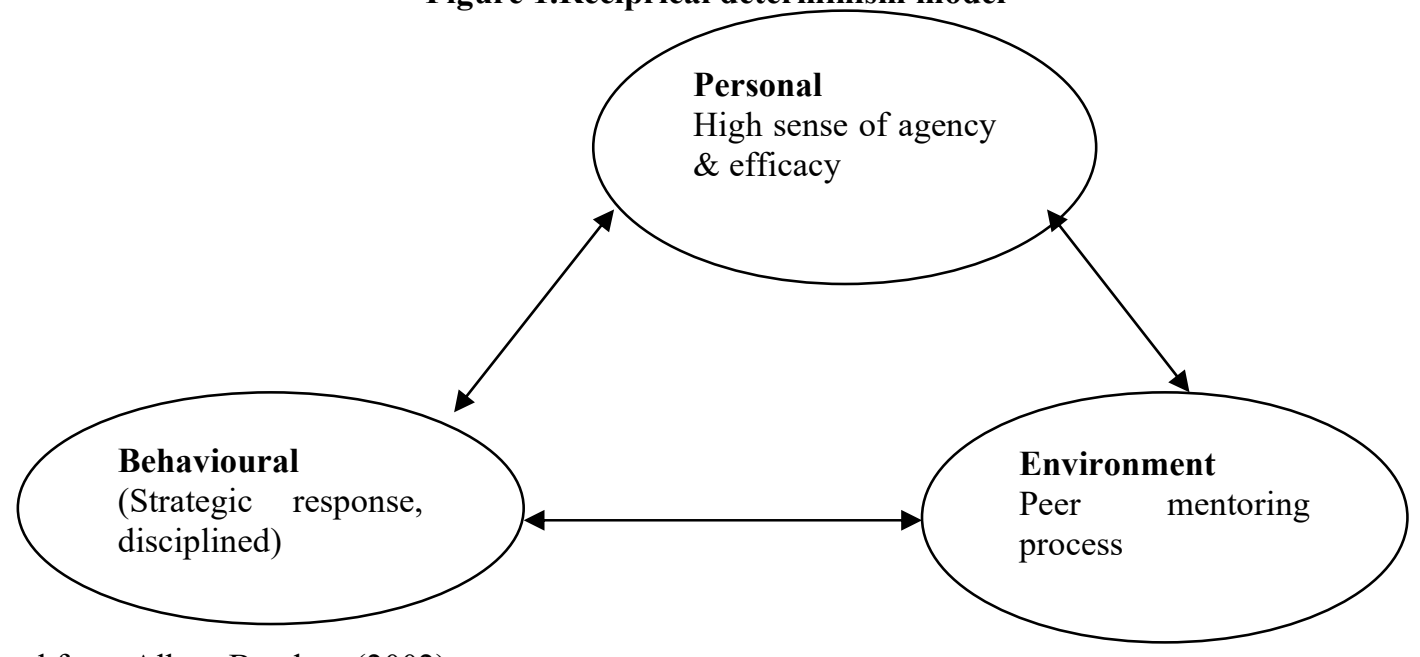

Adapted from Albert Bandura (2002) 